\title{
Nomogram to predict survival of patients with advanced and metastatic pancreatic cancer
}

\author{
Guochao Deng \\ Nankai University School of Medicine \\ Yao Lv \\ Chinese PLA General Hospital \\ Huan Yan \\ Chinese PLA General Hospital \\ Quan-li Han \\ Chinese PLA General Hospital \\ Guang-hai Dai ( $\square$ daigh301@vip.sina.com ) \\ https://orcid.org/0000-0001-7508-274X
}

\section{Primary research}

Keywords: Nomogram, Pancreatic cancer, Prognosis, First-line chemotherapy, Laboratory parameters, Clinicopathological factors

Posted Date: July 22nd, 2020

DOl: https://doi.org/10.21203/rs.3.rs-43508/v1

License: (c) (i) This work is licensed under a Creative Commons Attribution 4.0 International License. Read Full License

Version of Record: A version of this preprint was published at BMC Cancer on November 15th, 2021. See the published version at https://doi.org/10.1186/s12885-021-08943-w. 


\section{Abstract \\ Background}

The nomogram is increasingly being used in tumor prognosis. Few nomograms estimate the survival of patients with advanced and metastatic pancreatic cancer. We aim to establish a comprehensive nomogram to predict the survival probability of advanced and metastatic pancreatic cancer.

\section{Methods}

A total of 323 patients with advanced and metastatic pancreatic cancer who underwent first-line chemotherapy from January 2010 to December 2018 were identified from the Chinese People's Liberation Army (PLA) General Hospital. The baseline nomogram was established with baseline variables of 323 patients. And 233 patients who had initial tumor responses to first-line chemotherapy were enrolled in chemotherapy response-based model. The 6-month survival probability was evaluated by multivariate logistic regression models. Discrimination and calibration of the nomogram were tested by the concordance index (C-index), calibration plots and Kaplan-Meier curves. The predictive accuracy and net benefit of the nomogram were performed via receiver operating characteristic (ROC) curve analysis and decision curve analysis (DCA), respectively.

\section{Results}

In the baseline model, the 4 variables (KPS, gender, baseline CA 19 - 9 and baseline LDH) were enrolled in the final model. In the chemotherapy response-based model, the 5 variables (KPS, gender, baseline CA 19 -9 , the initial response to chemotherapy and second-line chemotherapy) were included in nomogram. The C-index of the two nomograms was $0.704(95 \% \mathrm{Cl}, 0.65-0.76)$ and $0.846(95 \% \mathrm{Cl}, 0.79-0.89)$, respectively. The Hosmer-Lemeshow test $x^{2}$ statistics were $4.182(p=0.840)$ and 9.427( $\left.P=0.323\right)$, respectively. Both two nomograms with good performance were demonstrated by the calibration plots.

\section{Conclusion}

The nomograms had been established to predict the survival probability of advanced and metastatic pancreatic cancer who underwent first-line chemotherapy. And the chemotherapy response-based model was better than the baseline model.

\section{Introduction}

Pancreatic cancer (PC) is the digestive malignancy cancer with high mortality. In worldwide, PC is the seventh cause of cancer-related deaths[1]. And in China, PC is the sixth cause of cancer-related mortality[2]. Now, the 5-year survival rate of PC is lower than 7\%[3]. For patients with advanced or 
metastatic PC, the comprehensive therapies based on chemotherapy was the primary choice. The preferred chemotherapy regimens recommended by National Comprehensive Cancer Network (NCCN) guidelines are FOLFIRINOX ((5-FU, leucovorin, irinotecan, and oxaliplatin) or gemcitabine plus albuminbound paclitaxel for patients with great performance status and gemcitabine monotherapy or 5FU/capecitabine for patients with poor performance status[4]. The median overall survival time of all chemotherapy regimens are so far less than 1 year[5].

The chemotherapy effect of advanced or metastatic PC varies from patients; thus, evaluating the prognosis of patients with their different conditions was essential for the patients and oncologists. Previous studies had found that some risk factors had the relationship with survival[6-9]. And most predictive models could select some individual predictive factors, but they could not calculate survival probability[10-12]. Nevertheless, the patients and physicians pay more attention to the survival probability.

Nomogram could evaluate the survival probability of patients with the specific scoring system[13, 14]. And nomograms have been used in different cancers for predicting survival rate[15, 16]. Few studies used the nomograms to predict the survival rate of patients with advanced or metastatic $P C[17,18]$. And most of the models were constructed by baseline clinicopathological factors[19]. But the responses of chemotherapy or sensitivity to chemotherapy are also crucial for predictive models of patients with chemotherapy treatment.

Therefore, we aim to develop the baseline model with baseline factors and the chemotherapy responsebased model with the factors contained the initial response to chemotherapy and changes in tumor markers after 2 cycles chemotherapy.

\section{Patients And Methods}

\section{Patient Population}

Patients with advanced and metastatic PC from January 2010 to December 2018 were identified from the Chinese People's Liberation Army (PLA) General Hospital. Patients who underwent first-line chemotherapy were enrolled in this study. We would perform the follow-up evaluations every 6 months by telephone or medical records.

The inclusion criteria were as follows: (1) diagnosis confirmed by histopathology or cytological; (2) Karnofsky performance status (KPS)score $\geq 70$; (3) without first-line chemotherapy previously; (3) finishing computed tomography (CT) evaluable before starting first-line chemotherapy;(4)collecting complete baseline information before first-line chemotherapy; (5) availability of evaluation with CT scans at 6-week (before the 3rd cycle chemotherapy); (6) 6-week laboratory factors obtained before the 3rd cycle chemotherapy; (7) having explicit terminal status. 
323 patients were selected into the baseline model according to these criteria. And among these patients, 233 patients who had initial tumor responses to first-line chemotherapy were enrolled into the chemotherapy response-based model, because they had been evaluated with CT scans before the third cycle chemotherapy. We chose the time point of 6 weeks from the beginning of first-line chemotherapy because the chemotherapy regimens were given with 3-week cycle and the evaluation was accomplished before the start of 3rd cycle chemotherapy. In our study, there are 134 patients were treated with nabpaclitaxel plus S-1 regimen; it's a clinical trial (NPSPAC) which was a single-arm, single-center and phase II trial in our hospital (https://clinicaltrials.gov/ number, NCT02124317).

\section{Clinicopathological Variables}

Demographic and clinicopathological variables were collected: gender, age, BMI, KPS, smoke, alcohol, diabetes, jaundice, ascites, metastatic sites, the total number of

metastasized organs, primary tumor location. The laboratory values were collected as following: white blood cell (WBC), platelet (PLT), neutrophil (N), albumin (Alb), lactate dehydrogenase (LDH), total bilirubin (TB), serum carcinoembryonic antigen (CEA), serum carbohydrate antigen 19-9 (CA 19-9). And 6-week serum albumin, 6-week lactate dehydrogenase (LDH), 6-week total bilirubin concentrations, 6-week carcinoembryonic antigen (CEA), 6-week carbohydrate antigen 19-9 (CA 19-9). Tumor lesion was assessed by CT scans before first cycle chemotherapy and after two cycles of chemotherapy. Chemotherapy efficacy was evaluated by Response Evaluation Criteria In Solid Tumors (RECIST version 1.0), and the patients were classified into progressive disease (PD) or non-progressive disease (non-PD), according to tumor responses. The changes in tumor markers levels at 6-week were defined as value measured at 6 -week subtraction the baseline value and divided by the baseline value. For example, \{change in LDH value at 6-week $=([\mathrm{LDH}$ at week-6] $-[\mathrm{LDH}$ at baseline] $) /(\mathrm{LDH}$ at baseline $)\}$. According to the value of the results, the patients were divided into two categories: the value with zero or more would be defined as no change and increase group and the value less than zero was defined as decrease group.

\section{Statistical Analysis}

Continuous predictors were expressed by medians with interquartile ranges (IQRs), and categorical predictors were described by numbers and proportions. Continuous

variables (i.e. age) were categorized into two groups according to their median levels. The correlation analysis of variables was evaluated by the correlation matrix. And multicollinearity diagnosis was performed by Variance inflation factor (VIF) using $\mathrm{R}$ version 3.6.3 software (car package in $\mathrm{R}$, http://www.r-project.org/). The value of VIF >10 means strong collinearity problems between variables. Otherwise, if the value of VIF was from 0 to 10, it means inexistence of collinearity problems between variables. Overall survival (OS) was the defined as the time interval from the date of beginning of first cycle chemotherapy to the date of death. The OS was converted into binary variable based on the overall survival time of patients whether exceeds six months. The relationships between variables and 6-month survival were assessed by univariate logistic regression analysis. The variables associated with 6-month 
survival at a significant level would be incorporated in multivariate logistic regression analysis. We used the backward stepwise selection with the Akaike information criterion (AIC) to choose variables. Based on the multivariate analysis, selected variables with statistics significantly were enrolled into the nomograms to predict the probability of 6-month survival using rms package in R. According to the proportional, the nomogram turned regression coefficient in multivariate logistic regression into 0 - to 100 -point scale. The point of each independent variable could be added together and derive total points to predicted probabilities.

The predictive model performance was evaluated by concordance index ( $\mathrm{C}$ index) and calibration. The Cindex is equal to the area under the receiver operating characteristic (ROC) curve. The closer the value of C-index was to 1, the better separation of patients with different outcomes. Calibration with 1000 bootstrap samples to reduce the overfitting was estimated by calibration plot. In a perfect calibrated model,

the prediction curve could coincide with the 45-degree diagonal line. The accuracy of the predictive model was evaluated by receiver operating characteristic (ROC) curve. We used Hosmer-Lemeshow $(\mathrm{H}-\mathrm{L}) x^{2}$ statistic to perform the model goodness-of-fit test, non-significant statistic means that the model fitted very well. The ROC analysis was performed by MedCalc15.2.2 with DeLong et al. method. And the net benefit of the model was assessed by decision curve analysis (DCA). We calculated total scores of patients predicted by the nomograms and used the X-tile version 3.6.1 (Yale University, CT, USA) to find the optimal cut-off value to stratify patients and performed Kaplan-Meier survival analysis (SPSS26.0). All statistical analyses were performed by R (version 3.6.3), SPSS26.0, X-tile (version 3.6.1) and MedCalc15.2.2. $P<0.05$ was considered statistically significant.

\section{Results}

\section{Clinical Characteristics of Patients}

Among the 323 patients, the median overall survival (mOS) was 10.6 months (95\% Cl: 9.7-11.7). 6month survival rate was $71.2 \%$ and 1 -year survival rate was $42.1 \%$.

Patient clinical characteristics in baseline model and chemotherapy response-based model are summarized in Table1. And the median levels with interquartile ranges (IQRs) of the continuous predictors are given in (TableS1, Supplement). In the two models, the median levels of the continuous variables are close. And the distribution of the data was similar in baseline model and chemotherapy response-based model. In the chemotherapy response-based model, 134 (57.5\%) patients treated with nab-paclitaxel plus S1 chemotherapy regimen, 31 (13.3\%) patients treated with gemcitabine monotherapy, 16 (6.9\%) patients treated with nab-paclitaxel plus gemcitabine, 41 (17.6\%) patients treated with gemcitabine-based combination chemotherapy, 4 (1.7\%) patients treated with S1 monotherapy, and 7 (3.0\%) patients treated with nab-paclitaxel monotherapy. 55(23.6\%) patients were progressive disease at the first evaluation after 2 cycle chemotherapy. 


\section{Development of Nomogram Prognostic Model}

All demographic and clinicopathological variables, as well as tumor markers were selected as candidate factors for developing the prediction model. In the baseline model, 7 variables were selected for multivariable analysis in univariate logistic analysis (Table2). And correlation analysis showed there were slight relationship between the seven factors (TableS2, Supplement). But the all values of variance inflation factor (VIF) were less than 2, it means that there were not collinearity problems between variables. In multivariable logistic analysis, we used backward stepwise with AIC to identify the 4 factors for final prediction model: KPS, gender, baseline CA 19-9 and baseline LDH (Table3).

Similarly, in the chemotherapy response-based model, 16 variables with statistical significance in univariate analysis were included in correlation analysis. Correlation analyses revealed strong relationship between number of metastasized organs and liver metastases $(r=0.626, P<0.001)$, and between baseline CEA and CEA level at week-6 ( $r=0.725, P<0.001)$ (TableS3, Supplement). The four variables were excluded from the multivariable analysis. The variance inflation factor (VIF) values of other variables were less than 3 . Thus, the other 11 variables were included in multivariable analysis. We used backward stepwise with AIC to identify the 5 factors for final nomogram model: KPS, gender, baseline CA 19-9, initial response to chemotherapy and second-line chemotherapy (Table3). Six-month survival probability can be evaluated by these nomograms (Fig.1, 2).

\section{Nomogram Validation}

In baseline model and chemotherapy response-based model, the C-index confirmed by the 1000 bootstrap validation was $0.704(95 \% \mathrm{Cl}, 0.65-0.76)$ and $0.846(95 \% \mathrm{Cl}, 0.79-0.89)$, respectively. The HosmerLemeshow test $x^{2}$ statistics were $4.182(p=0.840)$ and $9.427(p=0.323)$, respectively. The calibration curves were also observed good agreement between prediction and observation in baseline nomogram model and chemotherapy response-based nomogram model (Fig.3A,3B). And the model predictive accuracy between individual factors and combined factor was compared by ROC curves (Fig.4A,4B). The AUC of combined model was significantly larger than other individual predictors.

\section{Clinical use}

We used the X-tile to find the optimal cut-off value to stratify patients based on total scores predicted by the nomograms and then plotted Kaplan-Meier survival curves (Fig.5A, 5B). The baseline model stratified at 157 scores. The total score higher than 157 , the patients had better survival ( $\mathrm{HR}, 0.43 ; 95 \% \mathrm{Cl}, 0.33-0.57$; $\mathrm{P}<0.001)$. The chemotherapy response-based model stratified at 108 scores, the patients with higher scores than 108 had longer survival time $(H R, 0.16 ; 95 \% \mathrm{Cl}, 0.11-0.24 ; \mathrm{P}<0.001)$.

We also used decision curve analysis (DCA) to evaluated the net benefit and detected the clinical application value of nomogram models. In the two nomogram models, both the combined predictive models had better clinical utility than other single variables predictive value (Fig.6A, 6B). 


\section{Discussion}

In our study, we created 2 nomogram models that predicted the survival probability of patients with advanced PC who were treated with first-line chemotherapy. And the performance of nomograms was strictly assessed and internally validated. With a series of clinical trials being progressed, survival time of advanced PC has gradually increased, but the median overall survival was less than 1 year with palliative chemotherapy[5]. Based on the survival information of patients estimated by prognostic models, physicians could prescribe suitable treatment and timely adjust treatment plans.

Our study used the nomograms to predict 6-month survival probability. Good performance was shown in the baseline nomogram constructed by baseline clinical factors which easily obtained before chemotherapy. Therefore, physicians could gain

preliminary survival assessment at the time of diagnosis and then provide the dosage regimens for patients. After 2 cycles chemotherapy, we built chemotherapy response-based model which added treatment regimens, initial response to chemotherapy, and the changes level in tumor markers based on the baseline factors. The information could guide the physicians to decide on whether to adjust the treatment plan.

In this study, we collected a wide array of variables previously reported to be related to the prognosis of $P C[20,21]$. And some risk factors which have been reported to be associated with PC were also included in this study[22, 23]. In addition, previous studies showed that the changes level in tumor markers had relationship with survival of advanced PC $[24,25]$. For comprehensive assessment of patient survival, we collected more factors than other studies. However, we did not enroll all the variables into our model. After univariate analysis, we firstly performed abundant association analyses on all variables to avoid collinearity interference between variables. Then, we deleted the variables with high correlation coefficient $(r>0.5, P<0.05)$. Finally, we calculated the variance inflation factor $(V I F)$ to check collinearity problems. Thus, our study collected as much detailed information as possible while assuring the accuracy of prognosis. And at the same time, these variables were repeatedly validated in different studies which could help us to select and find the most effective information from a large amount of clinical information to improve clinical work efficiency.

Our baseline model and chemotherapy response-based model demonstrated good discriminative ability, the C-index were 0.704 and 0.846 , respectively. The baseline model was similar with previous studies[21, 26]. In our two models, the baseline CA 19 - 9 level was important factor for advanced PC. Previous studies had same results[20,21,27]. In the chemotherapy response-based model, we added some information into models to improve the value of prognosis, such as treatment information, initial response to chemotherapy, important laboratory markers. Because survival information could be infected by treatment process. We found that chemotherapy regimens, the initial response to chemotherapy and changes levels in markers at 6-week had relationship with survival probability in univariate analyses. However, the final model did not contain chemotherapy regimens and changes levels in markers at 6week without statistically significant in multivariate analysis. In the multivariate analysis the initial 
response to chemotherapy with higher OR (odds ratio $=3.64$ ) than other variables was the most powerful variable. Initial response to chemotherapy also could be applied to predict other tumors[16, 28].

There are several limitations in our study. First, the retrospective study may exist biases; and our data collected from single center, so we need to combine multi-center database to increase the credibility of the results. Then, the subsequent treatments of patients may exist differences. However, we did not discuss this point in detail. Finally, our nomograms were only performed internal validation with bootstrap validation, in the future, we need to finish the externally validation.

\section{Conclusions}

Based on different clinical factors, we used nomograms to evaluate the survival probability of patients with advanced PC undergoing first-line chemotherapy. And we developed the two predictive models fitted very well: the baseline model and chemotherapy response-based model. The effect of the chemotherapy response-based model with higher AUC was better than the baseline model. We can make different treatment plans according to the different model information. In the future, we will further develop the predicted model with multi-center data and add external validation.

\section{Abbreviations}

KPS: Karnofsky performance status; CT: computed tomography; WBC : white blood cell; PLT: platelet; N: neutrophil; Alb: albumin; LDH: lactate dehydrogenase; TB: total bilirubin; CEA: carcinoembryonic antigen; CA 19-9: serum carbohydrate antigen 19-9; PD: progressive disease; IQRs: interquartile ranges; VIF: Variance inflation factor; OS: overall survival; AIC: Akaike information criterion; C-index: concordance index;

ROC: receiver operating characteristic; DCA: decision curve analysis;

AUC: area under the curve

\section{Declarations}

\section{Ethics approval and consent to participate}

Our study was approved by the ethics committee of PLA General Hospital. All treatments were performed in accordance with institutional guidelines and regulations. Clinical data retrieved electronically from the medical records of PLA General Hospital Registry.

\section{Consent for publication}

Not applicable. 
The data used to support the findings of this study are available from the corresponding author upon request.

\section{Competing interests}

The authors declare that they have no competing interests

\section{Funding}

Research was supported by the projects from National Natural Science Foundation of China (81571411). The funding body has no role in the design of the study, collection, analysis, interpretation of data, and writing of the manuscript.

\section{Author Contributions}

Guo-chao Deng and Yao LV contributed equally as co-first authors. Guo-chao Deng and Yao LV participated in the main work. Guo-chao Deng designed this study and drafted and revised this manuscript. Guo-chao Deng and Yao Lv participated in acquisition of data, interpretation of data and analysis of data. Huan Yan participated in analysis of data and proofreading data. All authors read and approved the final manuscript.

\section{Acknowledgements}

Not applicable

\section{References}

1. Bray F, Ferlay J, Soerjomataram I, Siegel RL, Torre LA, Jemal A. Global cancer statistics 2018: GLOBOCAN estimates of incidence and mortality worldwide for 36 cancers in 185 countries. CA Cancer J Clin. 2018;68(6):394-424.

2. Wanqing Chen RZ, Peter D, Baade S, Zhang H, Zeng F, Bray. Ahmedin Jemal, Xue Qin Yu, Jie He: Cancer Statistics in China, 2015. CA CANCER J CLIN 2016.

3. Siegel RL, Miller KD, Jemal A. Cancer statistics, 2015. CA Cancer J Clin. 2015;65(1):5-29.

4. NCCN Guidelines Version 1.2019 Pancreatic Adenocarcinoma. Available from: https://wwwnccnorg/professionals/physician_gls/pdf/pancreaticpdf Accessed November 8, 2018.

5. Gupta R, Amanam I, Chung V. Current and future therapies for advanced pancreatic cancer. J Surg Oncol. 2017;116(1):25-34.

6. Chen Yuan VM-O, Babic A, Clish CB, Kraft P, Bao Y, Qian ZR, Rubinson DA, Ng K, Giovannucci EL, Ogino S, Stampfer MJ, Gaziano JM, Sesso HD, Cochrane BB, Manson JoAnnE. Charles S. Fuchs, and Brian M. Wolpin: cigarette smoking and pancreaticcancer survival. J Clin Onco/ 2017, 35(16).

7. Yuan C, Bao Y, Wu C, Kraft P, Ogino S, Ng K, Qian ZR, Rubinson DA, Stampfer MJ, Giovannucci EL, et al. Prediagnostic body mass index and pancreatic cancer survival. J Clin Oncol. 2013;31(33):4229- 
34.

8. Yuan C, Rubinson DA, Qian ZR, Wu C, Kraft P, Bao Y, Ogino S, Ng K, Clancy TE, Swanson RS, et al. Survival among patients with pancreatic cancer and long-standing or recent-onset diabetes mellitus. J Clin Oncol. 2015;33(1):29-35.

9. Ilic M, Ilic I. Epidemiology of pancreatic cancer. World J Gastroenterol. 2016;22(44):9694-705.

10. Jian-Guo Zhao YH, Liao Q, Niu Z-Y, Zhao Y-P. Prognostic significance of SUVmax and serum carbohydrate antigen 19 - 9 in pancreatic cancer.pdf. World J Gastroenterol. 2014;20(19):5875-80.

11. La Greca G, Sofia M, Lombardo R, Latteri S, Ricotta A, Puleo S, Russello D. Adjusting CA19-9 values to predict malignancy in obstructive jaundice: influence of bilirubin and C-reactive protein. World $\mathrm{J}$ Gastroenterol. 2012;18(31):4150-5.

12. Duranyildiz FTSKRCFSBSRDD. Serum levels of LDH, CEA, and CA19-9 have prognostic roles on survival in patients with metastatic pancreatic cancer receiving gemcitabine-based chemotherapy.pdf. Cancer Chemother Pharmacol. 2014;73:1163-71.

13. Zhang J-X, Song W, Chen Z-H, Wei J-H, Liao Y-J, Lei J, Hu M, Chen G-Z, Liao B, Lu J, et al. Prognostic and predictive value of a microRNA signature in stage II colon cancer: a microRNA expression analysis. The Lancet Oncology. 2013;14(13):1295-306.

14. Wang Y, Li J, Xia Y, Gong R, Wang K, Yan Z, Wan X, Liu G, Wu D, Shi L, et al. Prognostic nomogram for intrahepatic cholangiocarcinoma after partial hepatectomy. J Clin Oncol. 2013;31(9):1188-95.

15. Kim Y, Margonis GA, Prescott JD, Tran TB, Postlewait LM, Maithel SK, Wang TS, Evans DB, Hatzaras I, Shenoy R, et al. Nomograms to Predict Recurrence-Free and Overall Survival After Curative Resection of Adrenocortical Carcinoma. JAMA Surg. 2016;151(4):365-73.

16. Kim SY, Yoon MJ, Park YI, Kim MJ, Nam BH, Park SR. Nomograms predicting survival of patients with unresectable or metastatic gastric cancer who receive combination cytotoxic chemotherapy as first-line treatment. Gastric Cancer. 2018;21(3):453-63.

17. Choi SH, Park SW, Seong J. A nomogram for predicting survival of patients with locally advanced pancreatic cancer treated with chemoradiotherapy. Radiother Oncol. 2018;129(2):340-6.

18. Hang J, Wu L, Zhu L, Sun Z, Wang G, Pan J, Zheng S, Xu K, Du J, Jiang H. Prediction of overall survival for metastatic pancreatic cancer: Development and validation of a prognostic nomogram with data from open clinical trial and real-world study. Cancer Med 2018.

19. Fornaro L, Leone F, Vienot A, Casadei-Gardini A, Vivaldi C, Lièvre A, Lombardi P, De Luca E, Vernerey D, Sperti E, et al. Validated Nomogram Predicting 6-Month Survival in Pancreatic Cancer Patients Receiving First-Line 5-Fluorouracil, Oxaliplatin, and Irinotecan. Clinical Colorectal Cancer. 2019;18(4):e394-401.

20. Hamada T, Nakai Y, Yasunaga H, Isayama H, Matsui H, Takahara N, Sasaki T, Takagi K, Watanabe T, Yagioka $\mathrm{H}$, et al. Prognostic nomogram for nonresectable pancreatic cancer treated with gemcitabine-based chemotherapy. Br J Cancer. 2014;110(8):1943-9.

21. Zhang LX, Chen L, Xu AM. A Simple Model Established by Blood Markers Predicting Overall Survival After Radical Resection of Pancreatic Ductal Adenocarcinoma. Front Oncol. 2020;10:583. 
22. Anderson MA, Zolotarevsky E, Cooper KL, Sherman S, Shats O, Whitcomb DC, Lynch HT, Ghiorzo P, Rubinstein WS, Vogel KJ, et al. Alcohol and tobacco lower the age of presentation in sporadic pancreatic cancer in a dose-dependent manner: a multicenter study. Am J Gastroenterol. 2012;107(11):1730-9.

23. Li D, Morris JS, Liu J, Hassan MM, Day RS, Bondy ML, Abbruzzese JL. Body mass index and risk, age of onset, and survival in patients with pancreatic cancer. JAMA. 2009;301(24):2553-62.

24. Chiorean EG, Von Hoff DD, Reni M, Arena FP, Infante JR, Bathini VG, Wood TE, Mainwaring PN, Muldoon RT, Clingan PR, et al. CA19-9 decrease at 8 weeks as a predictor of overall survival in a randomized phase III trial (MPACT) of weekly nab-paclitaxel plus gemcitabine versus gemcitabine alone in patients with metastatic pancreatic cancer. Ann Oncol. 2016;27(4):654-60.

25. Michael Haas RPL, Petra Stieber SH, Christiane J, Bruns R, Wilkowski U, Mansmann V, Heinemann, Stefan Boeck: Prognostic relevance of CA 19 - 9, CEA, CRP, and LDH kinetics in patients treated with palliative second-line therapy for advanced pancreatic cancer. Tumor Biol 2010, 31:351-357.

26. Chen LT, Macarulla T, Blanc JF, Mirakhur B, Jong FA, Belanger B, Bekaii-Saab T, Siveke JT. Nomogram for Predicting Survival in Patients Treated with Liposomal Irinotecan Plus Fluorouracil and Leucovorin in Metastatic Pancreatic Cancer. Cancers 2019, 11(8).

27. Viviane Hess BG, Philipp Grawe D, Dietrich G, Bodoky T, Ruhstaller E, Bajetta P, Saletti A, Figer. Werner Scheithauer, Richard Herrmann: CA19-9 tumour-marker response to chemotherapy in patients with advanced pancreatic cancer enrolled in a randomised controlled trial. Lancet Oncol. 2008;9(9):1328.

28. Piessevaux H, Buyse M, Schlichting M, Van Cutsem E, Bokemeyer C, Heeger S, Tejpar S. Use of early tumor shrinkage to predict long-term outcome in metastatic colorectal cancer treated with cetuximab. J Clin Oncol. 2013;31(30):3764-75.

\section{Tables}

Table1. Patient Characteristics 


\begin{tabular}{|c|c|c|}
\hline \multirow[t]{2}{*}{ Characteristic } & Baseline model & Chemotherapy response-based model \\
\hline & N Percent (\%) & N Percent (\%) \\
\hline \multicolumn{3}{|l|}{ Gender } \\
\hline Female & $125(38.7)$ & $89(38.2)$ \\
\hline Male & 198(61.3) & $144(61.9 \rrbracket$ \\
\hline \multicolumn{3}{|l|}{ Age(year) } \\
\hline$\leq 56$ & $169(52.3)$ & $129(55.4 \rrbracket$ \\
\hline$\varangle 56$ & 154(47.7) & 104(44.6区 \\
\hline \multicolumn{3}{|l|}{$\mathrm{BMI}\left(\mathrm{kg} / \mathrm{m}^{2}\right)$} \\
\hline$\leq 25$ & $245(75.9)$ & 168(72.1区 \\
\hline$\varangle 25$ & $78(24.1)$ & 65(27.9ه \\
\hline \multicolumn{3}{|l|}{ KPS } \\
\hline $70 \sim 80$ & $95(29.4)$ & 86(36.9ه \\
\hline $90 \sim 100$ & 228(70.6) & 147(63.1区 \\
\hline \multicolumn{3}{|l|}{ Smoke } \\
\hline Absent & $202(62.5)$ & 148(63.5区 \\
\hline Present & $121(37.5)$ & 85(36.5区 \\
\hline \multicolumn{3}{|l|}{ Alcohol } \\
\hline Absent & $191(59.1)$ & 135(57.9ه \\
\hline Present & $132(40.9)$ & 98(42.1区 \\
\hline \multicolumn{3}{|l|}{ Diabetes } \\
\hline Absent & $255(78.9)$ & 183(78.5区 \\
\hline Present & $68(21.1)$ & $50(21.5 \rrbracket$ \\
\hline \multicolumn{3}{|l|}{ Jaundice } \\
\hline Absent & $254(78.6)$ & 185(79.4区 \\
\hline Present & $69(21.4)$ & 48(20.6》 \\
\hline \multicolumn{3}{|l|}{ Ascites } \\
\hline Absent & $244(75.5)$ & 174(74.7区 \\
\hline Present & $79(24.5)$ & 59(25.3囚 \\
\hline
\end{tabular}




\begin{tabular}{|lll|}
\hline Number of metastasized organs & & \\
\hline 0 & $55(17.0)$ & $33(14.2 \rrbracket$ \\
\hline 1 & $195(60.4)$ & $145(62.2 \rrbracket$ \\
\hline Liver metastases & $73(22.6)$ & $55(23.6 \rrbracket$ \\
\hline Absent & & \\
\hline Present & $74(22.9)$ & $48(20.6 \rrbracket$ \\
\hline Lung metastases & $249(77.1)$ & $185(79.4 \rrbracket$ \\
\hline Absent & & \\
\hline Present & $266(82.4)$ & $190(81.5 \rrbracket$ \\
\hline Bone metastases & $57(17.6)$ & $43(18.5 \rrbracket$ \\
\hline Absent & & \\
\hline Present & $294(91.0)$ & $213(91.4 \rrbracket$ \\
\hline
\end{tabular}

(Continue) 


\begin{tabular}{|c|c|c|}
\hline \multirow[t]{2}{*}{ Characteristic } & Baseline model & Chemotherapy response-based model \\
\hline & Percent (\%) & Percent (\%) \\
\hline \multicolumn{3}{|c|}{ Primary tumor location } \\
\hline Head & $121(37.5)$ & 86(36.9ه \\
\hline Body-Tail & $202(62.5)$ & 147(63.1区 \\
\hline \multicolumn{3}{|c|}{ Baseline WBC (×1000/mm3) } \\
\hline$\leq$ Median & $162(50.2)$ & $113(48.5)$ \\
\hline$>$ Median & 161(49.8) & $120(51.5)$ \\
\hline \multicolumn{3}{|c|}{ Baseline PLT(×1000/mm3) } \\
\hline$\leq$ Median & 162(50.2) & $120(51.5)$ \\
\hline > Median & $161(49.8)$ & $113(48.5)$ \\
\hline \multicolumn{3}{|l|}{ Baseline N } \\
\hline$\leq$ Median & $162(50.2)$ & 113(48.5) \\
\hline > Median & 161(49.8) & $120(51.5)$ \\
\hline \multicolumn{3}{|l|}{ Baseline Alb } \\
\hline$\leq$ Median & 164(50.8) & $121(51.9)$ \\
\hline$>$ Median & $159(49.2)$ & 112(48.1) \\
\hline \multicolumn{3}{|l|}{ Baseline LDH } \\
\hline$\leq$ Median & $155(48.0)$ & $116(49.8)$ \\
\hline > Median & $168(52.0)$ & $117(50.2)$ \\
\hline \multicolumn{3}{|l|}{ Baseline CEA } \\
\hline$\leq$ Median & 161(49.8) & $115(49.4)$ \\
\hline > Median & $162(50.2)$ & $118(50.6)$ \\
\hline \multicolumn{3}{|c|}{ Baseline CA 19-9 } \\
\hline$\leq$ Median & $162(50.2)$ & $112(48.1)$ \\
\hline$>$ Median & 161(49.8) & $121(51.9)$ \\
\hline \multicolumn{3}{|l|}{ Baseline TB } \\
\hline$\leq$ Median & $164(50.8)$ & 121(51.9) \\
\hline
\end{tabular}




\begin{tabular}{|c|c|c|}
\hline$>$ Median & 159(49.2) & 112(48.1) \\
\hline Change in TB level at week- 6 & NI & \\
\hline Decrease & & 154(66.1区 \\
\hline No change and increase & & 79(33.9凶 \\
\hline Change in LDH level at week- 6 & NI & \\
\hline Decrease & & 80(34.3区 \\
\hline No change and increase & & 153(65.7) \\
\hline Change in CEA level at week- 6 & NI & \\
\hline Decrease & & 93(39.9) \\
\hline No change and increase & & $140(60.1)$ \\
\hline Change in CA19-9 level at week-6 & NI & \\
\hline Decrease & & $151(64.8)$ \\
\hline No change and increase & & $82(35.2)$ \\
\hline \multirow[t]{2}{*}{ Characteristic } & Baseline model & Chemotherapy response-based model \\
\hline & N Percent (\%) & N Percent (\%) \\
\hline Change in TB level at week- 6 & NI & \\
\hline Decrease & & $138(59.2)$ \\
\hline No change and increase & & $95(40.8)$ \\
\hline Alb level at week-6 & NI & \\
\hline$\leq$ Median & & $117(50.2)$ \\
\hline$>$ Median & & $116(49.8)$ \\
\hline LDH at week-6 & NI & \\
\hline$\leq$ Median & & $113(48.5)$ \\
\hline > Median & & $120(51.5)$ \\
\hline CEA at week-6 & NI & \\
\hline$\leq$ Median & & 11750.2) \\
\hline > Median & & $116(49.8)$ \\
\hline CA 19-9 at week-6 & NI & \\
\hline$\leq$ Median & & $114(48.9)$ \\
\hline
\end{tabular}




\begin{tabular}{|lll|}
\hline MB at week-6 & NI & $119(51.1)$ \\
\hline$\leq$ Median & & \\
\hline$>$ Median & & $122(52.4)$ \\
\hline Initial response to chemotherapy & NI & $111(47.6)$ \\
\hline PD & & \\
\hline Non-PD & & $55(23.6)$ \\
\hline Chemotherapy regimen & NI & $178(76.4)$ \\
\hline nab-paclitaxel plus S1 & & \\
\hline Non nab-paclitaxel plus S1 & & $134(57.5)$ \\
\hline Second-line chemotherapy & NI & $99(42.5)$ \\
\hline No & & $117(50.4)$ \\
\hline Yes & & $115(49.6)$ \\
\hline Previous Surgery & & \\
\hline No & $306(94.7)$ & $221(94.8)$ \\
\hline Yes & $17(5.3)$ & $12(5.2)$ \\
\hline
\end{tabular}

Table2. Results of Univariate Logistic Regression Analysis 


\begin{tabular}{|c|c|c|c|c|c|c|}
\hline \multirow[t]{2}{*}{ Characteristic } & \multicolumn{3}{|c|}{$\begin{array}{l}\text { Baseline model } \\
(\mathrm{N}=323)\end{array}$} & \multicolumn{3}{|c|}{$\begin{array}{l}\text { Chemotherapy response-based } \\
\text { model }(N=233)\end{array}$} \\
\hline & OR & $95 \% \mathrm{Cl}$ & $\begin{array}{l}P \text { - } \\
\text { value }\end{array}$ & OR & $95 \% \mathrm{Cl}$ & P-value \\
\hline Gender (female vs male) & 0.56 & $0.34-0.90$ & 0.018 & 0.39 & $0.22-0.72$ & 0.002 \\
\hline $\operatorname{Age}(\leq 56$ vs $>56)$ & 0.79 & $0.51-1.25$ & 0.325 & 0.76 & $0.52-1.09$ & 0.136 \\
\hline $\mathrm{BMI}(\leq 25$ vs $>25)$ & 1.66 & $0.96-2.91$ & 0.071 & 1.35 & $0.92-1.96$ & 0.119 \\
\hline KPS (70 80 vs 90 100) & 2.72 & $1.66-4.65$ & $<0.001$ & 1.97 & $1.37-2.57$ & $<0.001$ \\
\hline Smoke (absent vs present) & 0.92 & $0.58-1.47$ & 0.735 & 0.77 & $0.44-1.32$ & 0.342 \\
\hline Alcohol (absent vs present) & 0.88 & $0.55-1.39$ & 0.579 & 0.70 & $0.41-1.20$ & 0.198 \\
\hline Diabetes (absent vs present) & 1.09 & $0.62-1.90$ & 0.766 & 1.12 & $0.58-2.16$ & 0.733 \\
\hline Jaundice (absent vs present) & 0.65 & $0.38-1.12$ & 0.118 & 0.92 & $0.47-1.78$ & 0.815 \\
\hline Ascites (absent vs present) & 0.81 & $0.48-1.37$ & 0.438 & 0.77 & $0.42-1.41$ & 0.392 \\
\hline \multicolumn{7}{|l|}{$\begin{array}{l}\text { Number of metastasized } \\
\text { organs }\end{array}$} \\
\hline 0 & & Reference & & & Reference & \\
\hline 1 & 1.60 & $0.77-3.32$ & 0.204 & 1.57 & $0.65-3.80$ & 0.319 \\
\hline$\geq 2$ & 1.43 & $0.82-2.46$ & 0.205 & 1.93 & $1.02-3.64$ & 0.042 \\
\hline $\begin{array}{l}\text { Liver metastases (absent vs } \\
\text { present) }\end{array}$ & 0.61 & $0.35-1.07$ & 0.087 & 0.54 & $0.29-0.99$ & 0.049 \\
\hline $\begin{array}{l}\text { Lung metastases (absent vs } \\
\text { present) }\end{array}$ & 0.83 & $0.46-1.49$ & 0.545 & 0.66 & $0.34-1.29$ & 0.221 \\
\hline $\begin{array}{l}\text { Bone metastases (absent vs } \\
\text { present) }\end{array}$ & 0.69 & $0.32-1.49$ & 0.352 & 0.66 & $0.26-1.67$ & 0.385 \\
\hline $\begin{array}{l}\text { Tumor location (Head vs Body- } \\
\text { Tail) }\end{array}$ & 1.14 & $0.72-1.83$ & 0.564 & 0.85 & $0.49-1.49$ & 0.571 \\
\hline Baseline WBC $(\leq 6.39$ vs $>6.39)$ & 0.51 & $0.31-0.80$ & 0.004 & 0.56 & $0.32-0.96$ & 0.035 \\
\hline Baseline PLT( $\leq 198$ vs >198) & 0.82 & $0.52-1.29$ & 0.396 & 0.91 & $0.53-1.55$ & 0.731 \\
\hline Baseline $\mathrm{N}(\leq 0.665$ vs $>0.665)$ & 0.53 & $0.34-0.84$ & 0.007 & 0.56 & $0.32-0.96$ & 0.036 \\
\hline $\begin{array}{l}\text { Baseline albumin }(\leq 40.5 \text { vs } \\
>40.5)\end{array}$ & 1.08 & $0.69-1.71$ & 0.715 & 1.03 & $0.60-1.76$ & 0.918 \\
\hline Baseline LDH( $\leq 159$ vs >159) & 0.52 & $0.32-0.82$ & 0.005 & 0.81 & $0.47-1.38$ & 0.442 \\
\hline Baseline CEA( $\leq 7.32$ vs $>7.32)$ & 0.54 & $0.34-0.86$ & 0.009 & 0.53 & $0.31-0.91$ & 0.022 \\
\hline
\end{tabular}




\begin{tabular}{|c|c|c|c|c|c|c|}
\hline $\begin{array}{l}\text { Baseline CA } 19-9 \text { ( } \leq 1453 \text { vs } \\
>1453)\end{array}$ & 0.45 & $0.28-0.72$ & 0.001 & 0.39 & $0.22-0.68$ & 0.001 \\
\hline $\begin{array}{l}\text { Baseline bilirubin( } \leq 11.4 \text { vs } \\
>11.4)\end{array}$ & 0.67 & $0.43-1.06$ & 0.087 & 0.76 & $0.45-1.30$ & 0.323 \\
\hline $\begin{array}{l}\text { Change in albumin level at } \\
\text { week-6 }\end{array}$ & & NI & & & & 0.889 \\
\hline Decrease & & & & 1 & 1 & \\
\hline No change and increase & & & & 0.96 & $0.55-1.69$ & \\
\hline Change in LDH level at week- 6 & & NI & & & & 0.597 \\
\hline Decrease & & & & 1 & 1 & \\
\hline No change and increase & & & & 1.17 & $0.66-2.06$ & \\
\hline Change in CEA level at week- 6 & & NI & & & & 0.018 \\
\hline Decrease & & & & 1 & 1 & \\
\hline No change and increase & & & & 1.98 & $1.12-3.49$ & \\
\hline $\begin{array}{l}\text { Change in CA19-9 level at } \\
\text { week-6 }\end{array}$ & & NI & & & & 0.001 \\
\hline Decrease & & & & 1 & 1 & \\
\hline No change and increase & & & & 2.51 & $1.43-4.39$ & \\
\hline Change in TB level at week- 6 & & NI & & & & 0.627 \\
\hline Decrease & & & & 1 & 1 & \\
\hline No change and increase & & & & 1.14 & $0.66-1.97$ & \\
\hline \multirow[t]{3}{*}{ Characteristic } & \multirow{2}{*}{\multicolumn{2}{|c|}{$\begin{array}{l}\text { Baseline model } \\
(\mathrm{N}=323)\end{array}$}} & & \multirow{2}{*}{\multicolumn{3}{|c|}{$\begin{array}{l}\text { Chemotherapy response-based } \\
\text { model } \\
(\mathrm{N}=233)\end{array}$}} \\
\hline & & & & & & \\
\hline & OR & $95 \% \mathrm{Cl}$ & $\begin{array}{l}\mathrm{P}- \\
\text { value }\end{array}$ & OR & $95 \% \mathrm{Cl}$ & P-value \\
\hline $\begin{array}{l}\text { Albumin at week- } 6 \text { ( } \leq 39.0 \text { vs } \\
>39.0)\end{array}$ & & NI & & 1.94 & $1.13-3.35$ & 0.017 \\
\hline $\begin{array}{l}\text { LDH at week-6( } \leq 170.7 \text { vs } \\
>170.7)\end{array}$ & & NI & & 1.18 & $0.69-2.02$ & 0.537 \\
\hline CEA at week-6( $\leq 7.97$ vs $>7.97)$ & & NI & & 0.46 & $0.27-0.80$ & 0.006 \\
\hline $\begin{array}{l}\text { CA } 19-9 \text { at week- } 6 \text { ( } \leq 790.7 \text { vs } \\
>790.7 \text { ) }\end{array}$ & & NI & & 0.43 & $0.25-0.74$ & 0.003 \\
\hline Bilirubin at week -6 ( $\leq 9.6$ vs & & NI & & 0.86 & $0.50-1.47$ & 0.588 \\
\hline
\end{tabular}




\begin{tabular}{|c|c|c|c|c|c|c|}
\hline $\begin{array}{l}\text { Initial response to } \\
\text { chemotherapy }\end{array}$ & & NI & & & & $<0.001$ \\
\hline PD & & & & 1 & 1 & \\
\hline Non-PD & & & & 5.13 & $2.68-9.79$ & \\
\hline Chemotherapy regimen & & NI & & & & 0.005 \\
\hline nab-paclitaxel plus S1 & & & & 1 & 1 & \\
\hline Non nab-paclitaxel plus S1 & & & & 2.19 & $1.27-3.78$ & \\
\hline Second-line chemotherapy & & NI & & & & $<0.001$ \\
\hline Yes & & & & 1 & 1 & \\
\hline No & & & & 3.05 & $1.74-5.34$ & \\
\hline Previous Surgery & & & 0.250 & & & 0.840 \\
\hline Yes & 1 & 1 & & 1 & 1 & \\
\hline No & 1.96 & $0.62-6.15$ & & 1.13 & $0.33-3.89$ & \\
\hline
\end{tabular}

Table3. Results of Multivariate Logistic Regression Analysis 


\begin{tabular}{|c|c|c|c|c|c|c|}
\hline \multirow[t]{2}{*}{ Characteristic } & \multicolumn{3}{|c|}{$\begin{array}{l}\text { Baseline model } \\
(\mathrm{N}=323)\end{array}$} & \multicolumn{3}{|c|}{$\begin{array}{l}\text { Chemotherapy response-based } \\
\text { model } \\
(\mathrm{N}=233)\end{array}$} \\
\hline & OR & $95 \% \mathrm{Cl}$ & $\begin{array}{l}\mathrm{P}- \\
\text { value }\end{array}$ & OR & $95 \% \mathrm{Cl}$ & P-value \\
\hline Gender (female vs male) & 0.49 & $\begin{array}{l}0.29- \\
0.81\end{array}$ & 0.006 & 0.38 & $0.18-0.78$ & 0.008 \\
\hline $\begin{array}{l}\text { KPS (70 80 vs } \\
90 \sim 100)\end{array}$ & 2.97 & $\begin{array}{l}1.77- \\
4.99\end{array}$ & $<0.001$ & 1.91 & $1.20-2.61$ & $<0.001$ \\
\hline Baseline CA 19-9 & 0.46 & $\begin{array}{l}0.28- \\
0.75\end{array}$ & 0.002 & 0.30 & $0.15-0.61$ & $<0.001$ \\
\hline Baseline LDH & 0.54 & $\begin{array}{l}0.33- \\
0.89\end{array}$ & 0.015 & & NI & \\
\hline Initial response to chemotherapy & & NI & & & & 0.001 \\
\hline PD & & & & 1 & 1 & \\
\hline Non-PD & & & & 3.64 & $1.67-7.96$ & \\
\hline Second-line chemotherapy & & NI & & & & 0.001 \\
\hline Yes & & & & 1 & 1 & \\
\hline No & & & & 3.09 & $1.55-6.14$ & \\
\hline
\end{tabular}

Figures 
Points

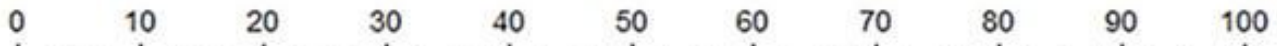

KPS

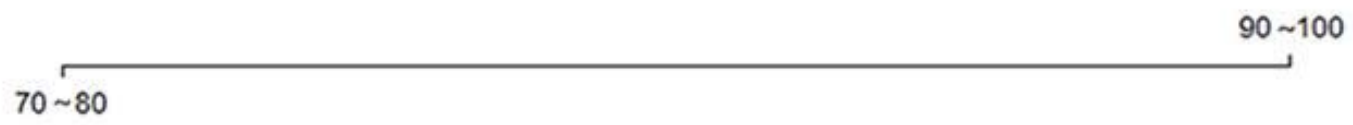

Gender

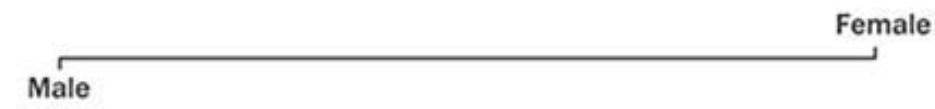

Baseline CA199

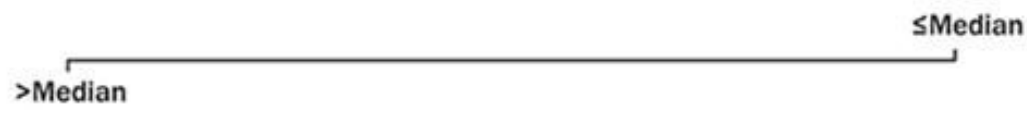

Baseline LDH

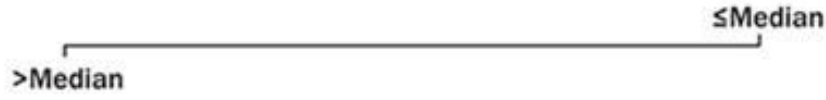

Total Points

$\begin{array}{llllll}1 & 150 & 200 & 250 & 300 & 350\end{array}$

6-month survival rate

\begin{tabular}{lllllll}
\hline & 0.3 & 1 & 1 & 1 & 1 & 1 \\
1 & 0.4 & 0.5 & 0.6 & 0.7 & 0.8 & 0.9
\end{tabular}

\section{Figure 1}

Baseline nomogram to predict 6-month survival rate of PC patients created based on 4 independent prognostic factors. 
Points

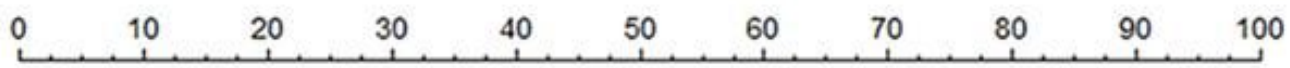

KPS

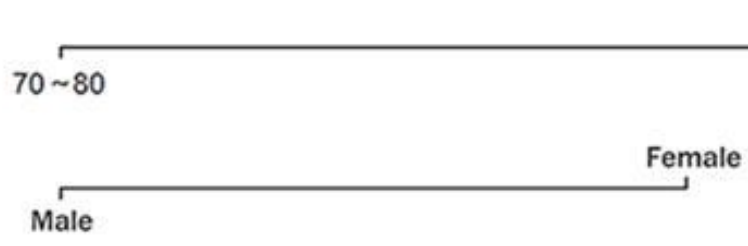

Gender

Baseline CA199

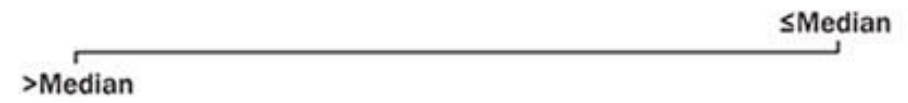

Initial response

to chemotherapy

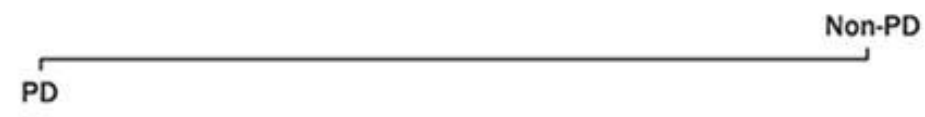

Second-line chemotherapy

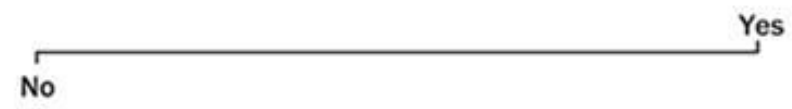

Total Points

$50 \quad 100 \quad 150 \quad 200 \quad 250 \quad 300 \quad 350 \quad 400$

6-month survival rate

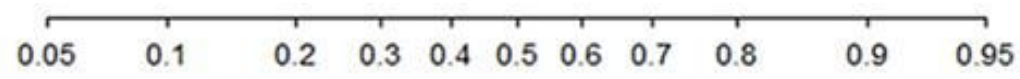

\section{Figure 2}

Chemotherapy response-based nomogram to predict 6-month survival rate of PC patients created based on 5 independent prognostic factors.
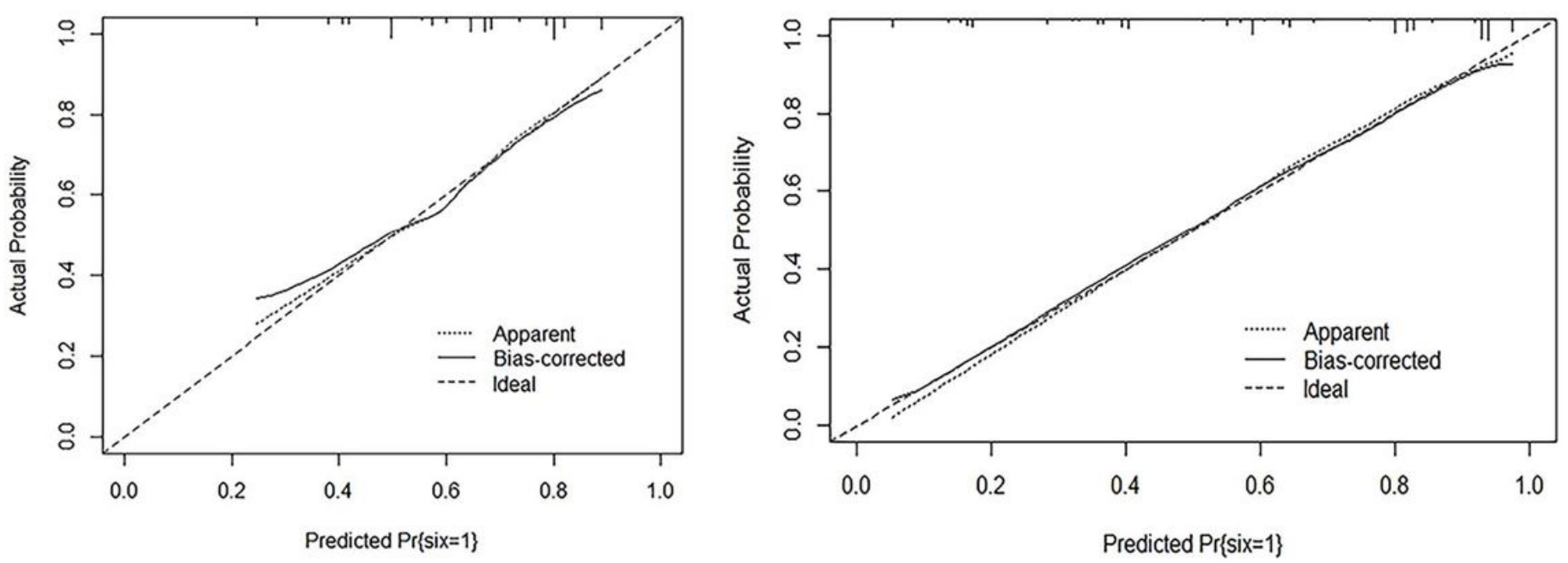
Figure 3

Calibration plot of nomogram comparing actual with predicted probabilities at 6-month survival rate. (A). Calibration plot of baseline nomogram; (B). Calibration plot of chemotherapy response-based nomogram.
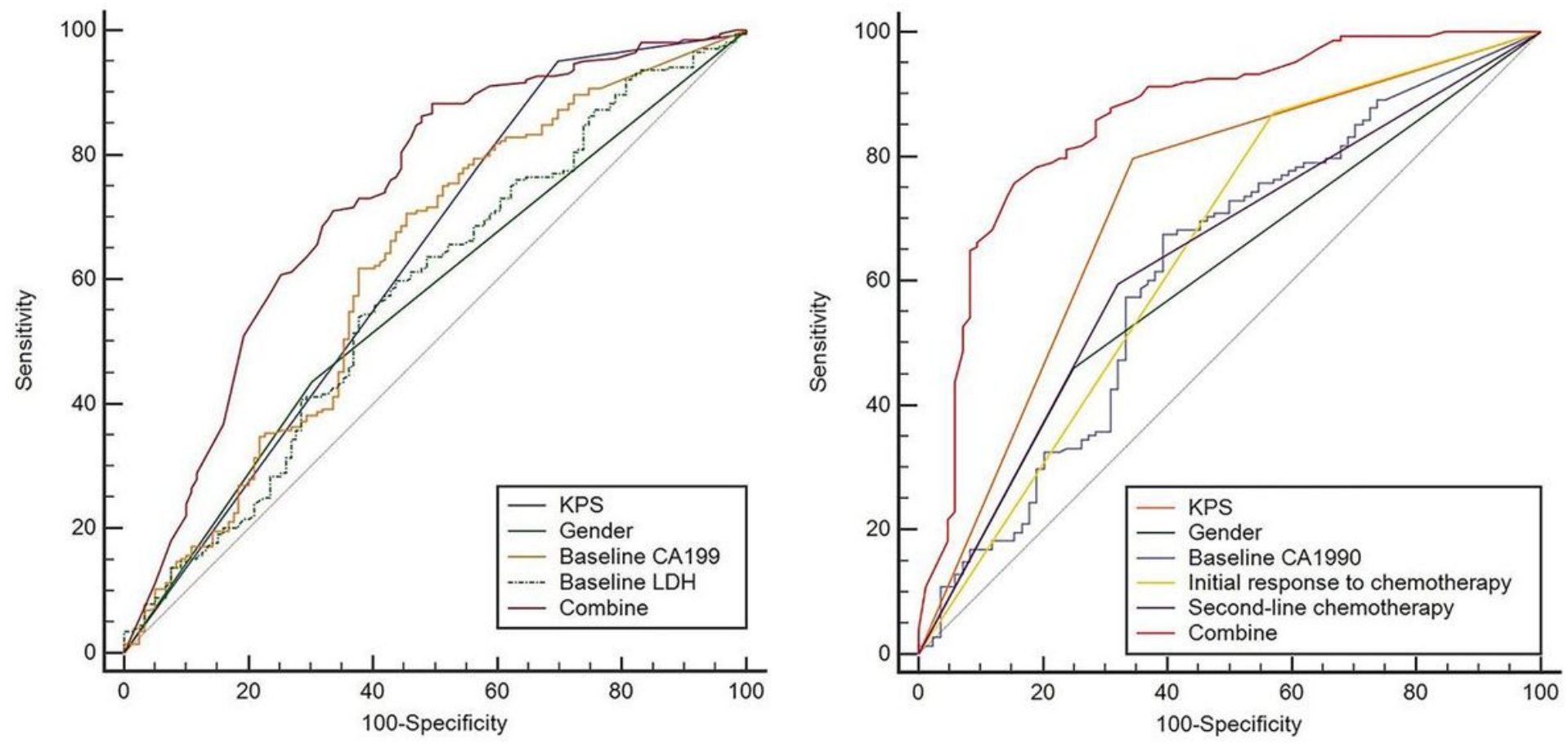

Figure 4

Time-dependent receiver operating characteristic (ROC) curve analysis of nomogram for 6-month survival. The combined nomogram (red solid line) had better accuracy than any other predictor. (A). ROC curve of baseline nomogram; (B). ROC curve of chemotherapy response-based nomogram. 

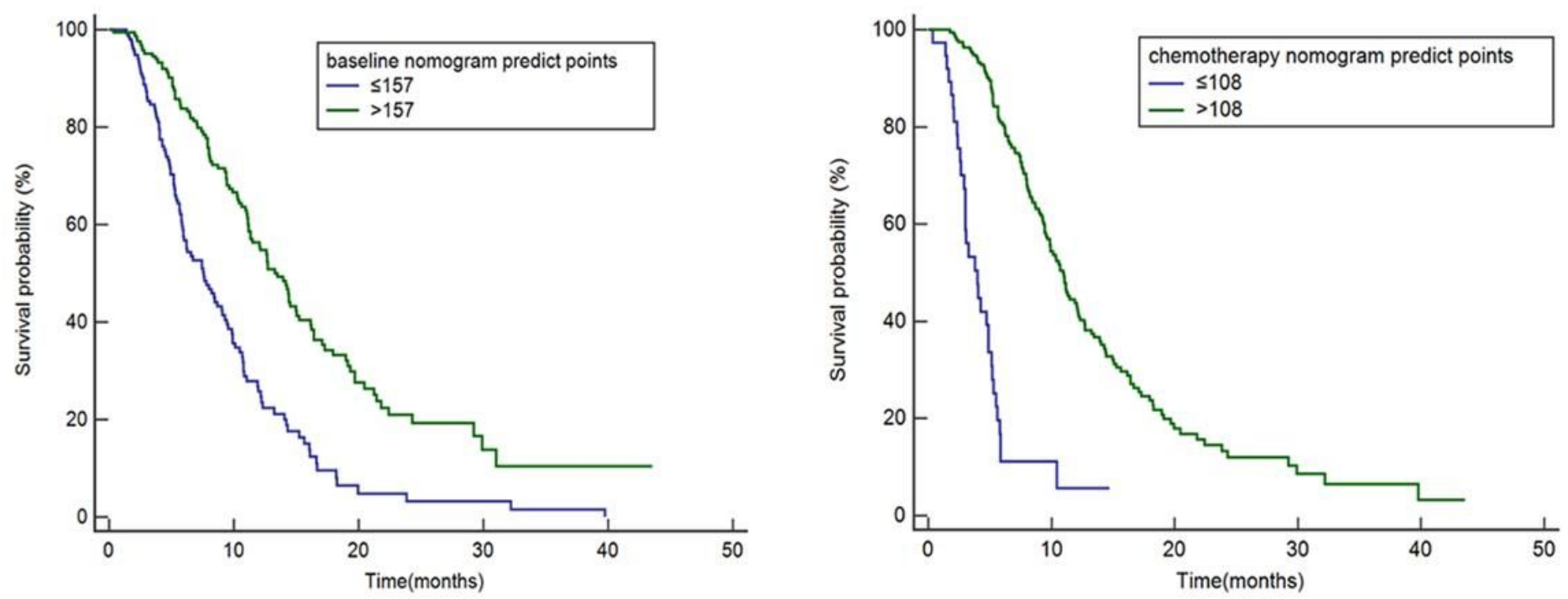

\section{Figure 5}

Kaplan-Meier Curves for patients stratified by nomogram predict points. (A). Kaplan-Meier Curves of patients in baseline nomogram; (B). Kaplan-Meier Curves of patients in chemotherapy response-based nomogram.
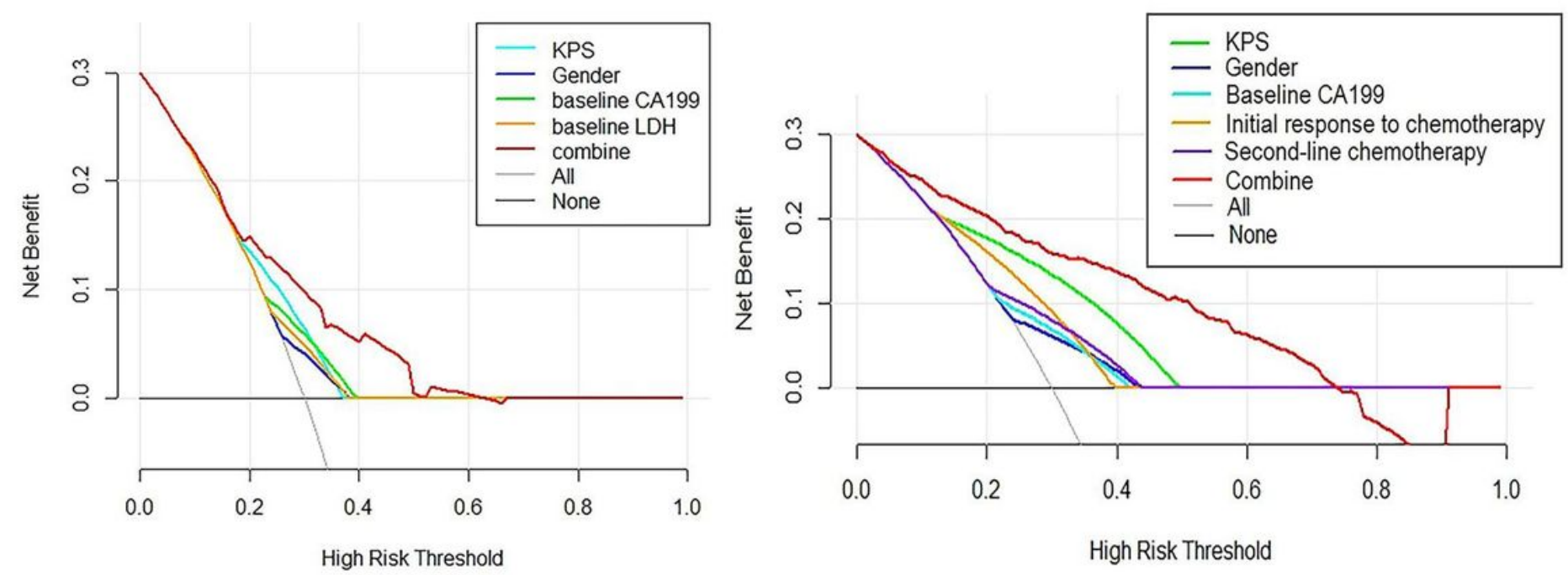

Figure 6

Decision curve analysis (DCA) of the nomogram for 6-month survival. The dark solid line represents the assumption that no patient survival in 6-month. The gray solid line represents the assumption that all 
patient survival in 6-month. The red solid line represents the combined nomogram. (A). DCA of baseline nomogram; (B). DCA of chemotherapy response-based nomogram. Both two DCA, the combined nomogram add benefit than individual predictive model.

\section{Supplementary Files}

This is a list of supplementary files associated with this preprint. Click to download.

- Additionalfile.docx 